\title{
KINESITHERAPEUTIC APPROACH IN PATIENTS WITH ISCHEMIC STROKE TREATED WITH VE- NOUS THROMBOLYSIS
}

\author{
Mariela Filipova $^{1}$, Daniela Popova ${ }^{1}$, Stanislava Bogomilova ${ }^{2}$, Gergana Nenova $^{2}$ \\ 1) Department of Kinesitherapy, Faculty of Public Health, health care and \\ sport, SWU “N. Rilski” Blagoevgrad, Bulgaria. \\ 2) Training sector of kinesitherapy, Faculty of Public health, Medical Univer- \\ sity, Varna, Bulgaria.
}

\begin{abstract}
:
Ischemic stroke is a social disorder that leads to a great degree of disability in the world. In recent years, in undeclared practice, new methodologies and assessment methods have been introduced that are not presented with regard to the possibility of determining the potential potential of individuals in choosing a stroke.

Methods: A total of 205 patients with ischemic stroke with a pronounced motor deficiency were investigated after an acute incident. Everyone has a history, clinical and paraclinical examinations, motor deficit and kinesitherapeutic potential.

Results and analysis: The result of the registration of the registered persons, which are intended for the best and best assessment of the condition.

Conclusion: In conclusion, we can say that the assessment is complex and the use of single tests is not appropriate. For the proper determination of the kinesitherapeutic potential, specialized tests should be used, which in turn provide a qualitative and rapid analysis of the condition of the patients.
\end{abstract}

Keywords: kinesitherapeutic potential, ischemic stroke, venous thrombolysis

\section{INTRODUCTION}

Ischemic stroke is a social disorder that leads to a great degree of disability in the world. The World Health Organization defines the cerebrovascular accident as a "syndrome of rapidly developing subjective and objective symptoms, long-term loss of brain function and symptoms, lasting for 24 hours or longer." [1, 2, 3, 4] In recent years, in undeclared practice, new methodologies and assessment methods have been introduced that are not presented with regard to the possibility of determining the potential. [2, 3, 5, 6] In the methodology, it is impressed that there were only few neurological tests of the daily life activities that are widely used for the kinesitherapeutic potential in the neurological practice in Bulgaria and abroad $[6,7]$.

The use of a variety of techniques for the complex treatment of patients with ischemic stroke requires knowl- edge of pathological changes in motor deficiency following an acute cerebrovascular accident as part of complex therapy [8]. So far, there is no unified kinesitherapeutic method of administration. Each of them has a definite impact, there are a number of benefits and disadvantages. This work explores the clinical practice of venous thrombolysis in patients with ischemic stroke, describes its occurrence, the experience gained by foreign practitioners, the recovery of patients in treatment clinics and rehabilitation centers and the results of the application of innovation in Bulgaria.

Venous thrombolysis reduces hospital stay. Time to recover the motor deficit is limited to a minimum, sometimes to hours. The possibility of using the procedure in patients with severe co-morbidity expands the choice of recanalization.

\section{METHODS}

A total of 205 patients with ischemic stroke with a pronounced motor deficiency were investigated after an acute incident. Everyone has a history, clinical and paraclinical examinations, engine deficit and kinesitherapeutic potential.

Criteria for exclusion from the study were patients with secondary hospitalization in previous years (114 cases), those with contractions in the affected limbs (22 cases) and patients with ischemic stroke in the vertebrobasilar system (29 cases).

This study included a total of 20 patients aged $65,70 \pm 8,18$ years. The study is conducted after informed consent of the patient and his or her relatives. The study was conducted in the period 2008-2014 in the Neurological Department at the University Hospital in Blagoevgrad. The following neurological tests were investigated: Mingazzini - Strümpell test, National Health Institutional Scale (NIHSS), a modified Ashworth test and test for the activities from daily life - the Barthel Index.

\section{RESULTS}

Twenty patients treated with the intervention in the neurological department of the Multiprofile Hospital for Active Treatment Blagoevgrad for 30 days were studied. 
The average age of the contingent is $65,70 \pm 8,18$ years. Patients were all tested for hospitalization and dehospitalisation. On the day of hospitalization, the patients receive an abnormal Cincinnati prehospital stroke test, and scoring in the NIHSS scale before thrombolysis shows values within 16-20 points and stroke severity from moder- ate stroke to severe cerebral accident - severe stroke. The sample of Mingazzini - Strümpell detects latent paresis. In our study, patients have a severe motor deficiency in hospitalization. On the 5-th day of the hospital stay, there was a significant change in the NIHSS values - the motor deficit is significantly reduced (fig.1).

Fig 1. NIHSS scale before and after hospitalization

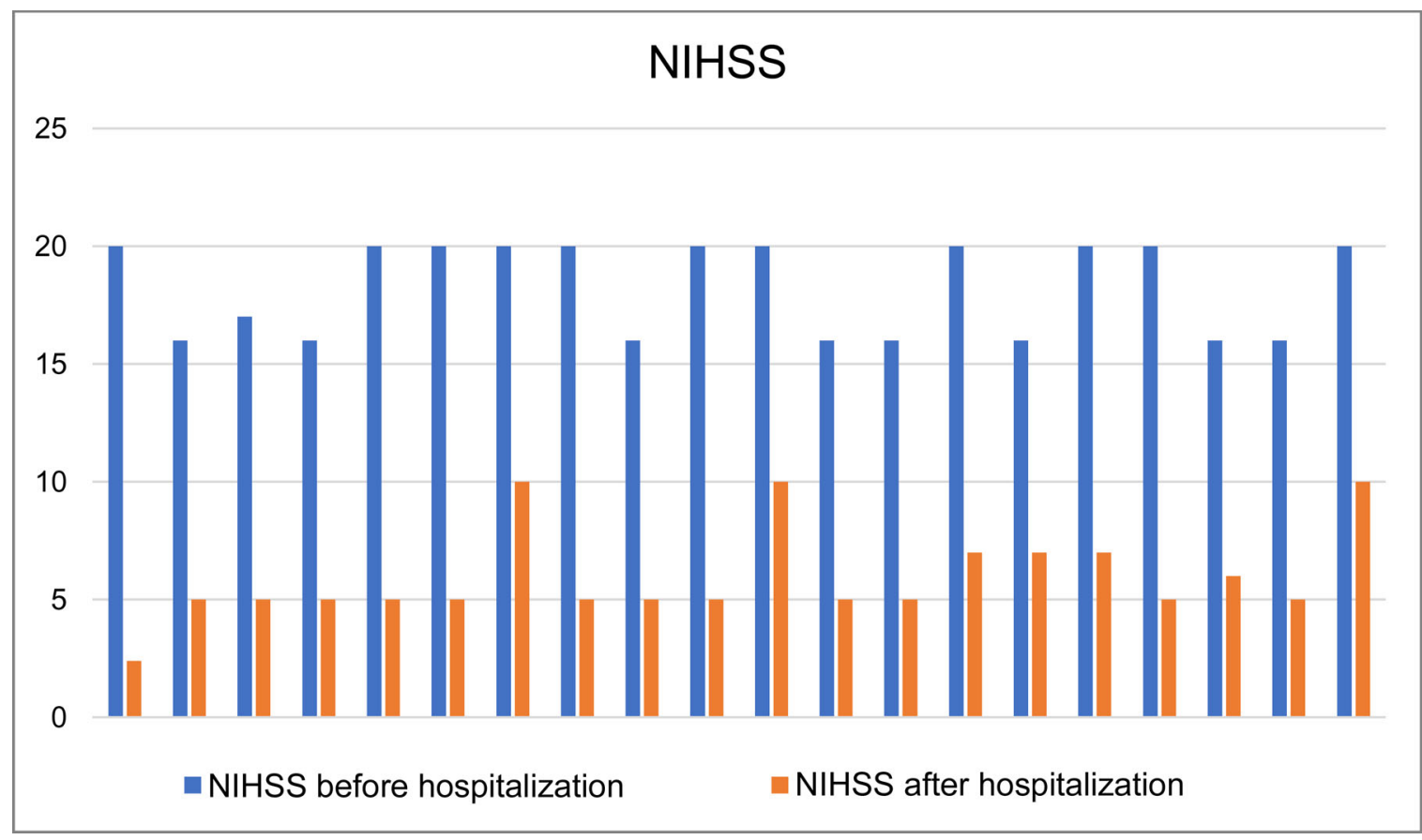

Comparison of the baseline and final baseline studies of the Barthel Index indicates that prior to kinesitherapeutic treatment, patients have limited mobility and are extremely difficult to carry out the activities of everyday life. The use of specialized tests serves to establish functional independence, restoring muscle strength, and a lack of tendency to enhance the pathology of muscle tone. The Chi-Square test is certified and the fourth is asymp. sigp $<0.05$ (in our study $\mathrm{p}=0.001$ ). This allows for a correct approximation, with a statistically signifi- cant difference between the initial and the final results.

\section{CONCLUSION}

In conclusion, we can say that the assessment is complex and the use of single tests is not appropriate. For the proper determination of the kinesitherapeutic potential, specialized tests should be used, which in turn provide a qualitative and rapid analysis of the condition of the patients.

\section{REFERENCES:}

1. Baehr M, Frotscher M. Corticospinal Tract (Pyramidal Tract); Corticonuclear (Corticobulbar) Tract. In: Duus' Topical Diagnosis in Neurology: Anatomy, Physiology, Signs, Symptoms. 4th edition. Thieme. August 10, 2005. Chapter 3. p.59. [Internet]

2. Bambauer KZ, Johnston SC, Bambauer DE, Zivin JA. Reasons why few patients with acute stroke receive tissue plasminogen activator. Arch Neurol. 2006 May;63(5):661-4.

\section{[PubMed] [Crossref]}

3. Bamford J, Sandercock P, Dennis M, Burn J, Warlow C. Classification and natural history of clinically identifiable subtypes of cerebral infarction. Lancet. 1991 Jun 22;337 (8756):1521-6. [PubMed] [Crossref]

4. Barreto AD, Sharma VK, Lao AY, Schellinger PD, Amarenco P, Sierzenski P, et al. Safety and DoseEscalation Study Design of Transcranial Ultrasound in Clinical SON olysis for Acute Ischemic Stroke: The
TUCSON Trial. Int J Stroke. 2009 Feb;4(1):42-8. [PubMed] [Crossref]

5. Milanov I. [Neurology.] Sofiia: Meditsina i fizkultura. 2012. pp.2831. [in Bulgarian]

6. Filipova M. Thrombolysis at kinesitherapy. Activit Phys Educ Sport. 2014; 4(1):67-68.

7. Filipova M, Popova D. Kinesitherapyand health care in patients with ischemic stroke treated with intravenous thrombolysis. Activit Phys Educ Sport. 2015; 5(2):194-196. 
8. Abukaresh A, Al-Abadlah R, Böttcher B, El-Essi K. Ischaemic stroke management at Al-Shifa Hospital in the Gaza Strip: a clinical audit. Lancet. 2018 Feb 21;391 Suppl 2: S7. [PubMed] [Crossref].

Please cite this article as: Filipova M, Popova D, Bogomilova S, Nenova G. Kinesitherapeutic approach in patients with ischemic stroke treated with venous thrombolysis. $J$ of IMAB. 2020 Oct-Dec;26(4):3371-3373. DOI: https://doi.org/10.5272/jimab.2020264.3371

Received: 20/08/2019; Published online: 07/10/2020

Address for correspondence:

Assoc. prof. Mariela Filipova,

Department of Kinesitherapy, Faculty of Public Health, health care and sport, SWU "Neofit Rilski" Blagoevgrad,

66, Ivan Mihaylov str., Blagoevgrad, Bulgaria.

E-mail: mariela_filipova@swu.bg 